\title{
A Multi-Criteria Approach to Evaluate Floating Offshore Wind Farms Siting in the Canary Islands (Spain)
}

\author{
Hugo Díaz (D) and Carlos Guedes Soares *(D) \\ Centre for Marine Technology and Ocean Engineering (CENTEC), Instituto Superior Técnico, \\ Universidade de Lisboa, 1000 Lisbon, Portugal; hugo.martinez@centec.tecnico.ulisboa.pt \\ * Correspondence: c.guedes.soares@centec.tecnico.ulisboa.pt
}

check for

updates

Citation: Díaz, H.; Soares, C.G. A Multi-Criteria Approach to Evaluate Floating Offshore Wind Farms Siting in the Canary Islands (Spain). Energies 2021, 14, 865. https://doi.org/ $10.3390 /$ en14040865

Academic Editor: Toshihiko Nakata Received: 31 December 2020

Accepted: 4 February 2021

Published: 7 February 2021

Publisher's Note: MDPI stays neutral with regard to jurisdictional claims in published maps and institutional affiliations.

Copyright: (c) 2021 by the authors. Licensee MDPI, Basel, Switzerland. This article is an open access article distributed under the terms and conditions of the Creative Commons Attribution (CC BY) license (https:// creativecommons.org/licenses/by/ $4.0 /)$.

\begin{abstract}
The study presents a methodology for floating wind farms site selection with a Canary Islands case study. The frame combines geographical information systems (GIS) and multiple criteria decision methods (MCDMs). First, the problematic areas for the installation of the turbines are identified through a GIS database application. This tool generates thematic layers representing exclusion criteria. Then, at the second stage of the study, available maritime locations are analyzed and ranked using the analytical hierarchy process (AHP), based on technical, economic, and environmental aspects. AHP's technique guarantee the elimination of the judgment's subjectivity. The study also compared the solutions of the AHP technique with other methods, such as Preference Ranking Organization METHod for Enrichment of Evaluations (PROMETHEE), ELimination Et Choix Traduisant la Realité (ELECTRE III), Technique for Order Preferences by Similarity to Ideal Solution (TOPSIS) and Weighted Sum Algorithm (WSA(). The main result of this study is the creation of a realistic and objective overview of floating offshore wind farm site selection and the contribution to minimize the environmental impacts and to reduce the social conflicts between stakeholders.
\end{abstract}

Keywords: Canary Islands; floating wind farm; multicriteria decision making; offshore wind; site selection; spatial energy planning

\section{Introduction}

The Canary Islands is a Spanish volcanic origin archipelago, situated in the north Atlantic between $39^{\circ} 45^{\prime}$ and $14^{\circ} 49^{\prime} \mathrm{N}$, and between $31^{\circ} 17^{\prime}$ and $13^{\circ} 20^{\prime} \mathrm{W}, 111 \mathrm{~km}$ off the northwestern coast of the African continent. Rugged coastlines and irregular marine seabed characterise the region. The littoral slope drops to significant depths near the coastline.

The Canary archipelago is comprised of seven major islands (Gran Canaria, Fuerteventura, Tenerife, Lanzarote, La Palma, La Gomera and El Hierro) along with a series on smaller islands and islets (Figure 1). The land surface covers $7542 \mathrm{~km}^{2}$, of which a total of $1490 \mathrm{~km}$ are coastline [1]. This archipelago emerged from the ocean because of the accumulation of lava from several volcanic eruptions due to the continental drift. The islands appeared separately, and the depths of the channels between them can reach 1500 to $2000 \mathrm{~m}$.

The Paris Agreement identified the islands as particularly vulnerable areas to climate change, and highly dependent on energy imports [2]. Almost $98 \%$ of energy consumption is based on fossil fuels. A huge percentage of Europe's islands are formed by small isolated energy systems and small energy markets. Nevertheless, 15 million Europeans live on islands. This characteristic makes islands potential areas to be frontrunners in the clean energy transition by implementing innovative solutions and adopting new technologies.

The Canary Islands have plenty of renewable resources, mainly solar and onshore wind. For an archipelago located a certain distance from the continent, it is crucial to increase the energy self-sufficiency. This is due to mainland electrical connection's impossibility due to the high cost and the electrical losses. Energy autonomy could be achieved 
with the help of renewable energy sources (RES). The major islands are powered through autonomous electrical grids. The only underwater cable connects the islands of Lanzarote and Fuerteventura.

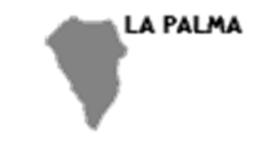

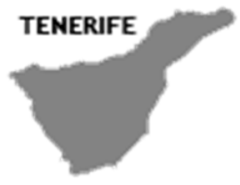
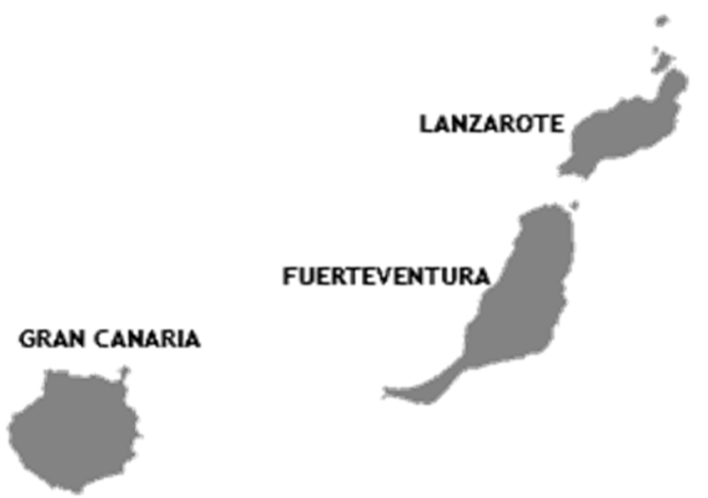

EL HIERRO

Figure 1. The Canary Islands archipelago, Spain (latitude, longitude: 28.291565, -16.629129).

The total gross electric power installed in the Canary Islands at the beginning of 2018 was $3120 \mathrm{MW}, 13.6 \%$ from renewable energies. The RES introduced in the Canary Islands is mainly wind and solar, 50.3\% and 43\%, respectively in 2017 [3].

The Energy Strategy 2025 for the Canary Islands establishes that $45 \%$ of the installed capacity should be renewable [4]. Nevertheless, available space is sparse in the archipelago, and over $40 \%$ of this surface is protected [5]. Find available space for renewable installations is complicated due to the competence with tourism, agriculture, and urbanistic developments. The uneven terrain makes an unsuitable area for a potential onshore wind farm, despite the relatively good wind conditions. On the other hand, the average water depth in the region is quite deep, unfeasible to installing fixed offshore wind turbines. Access is minimal, and the volcanic rock is not a firm foundation to wind turbine foundations.

There are not many floating wind turbines in commercial operation, although several prototypes are being tested in full scale [6]. There are several configurations of the support structure for the wind turbine [7]. Still, independently of the type of foundation, the various studies tend to increase wind turbines' power to increase their efficiency.

This study develops an integrated multi-criteria decision support framework for floating wind farm locations selection. Considering both issues and renewable energy targets, it is essential to identify the floating wind farms locations as the first step for energy development. A methodology based on Geographical Information Systems that includes environmental, technical, and economic criteria has been carried out. Therefore, the criteria importance is determined by applying pairwise comparison obtained from industry expert judgements. The pairwise comparisons follow the Analytical Hierarchy Process (AHP) method. The site selection is a generic process applied to the suitability assessment of any offshore wind project locations. Moreover, the solutions of the decision problem obtained from AHP are compared with the Preference Ranking Organization METHod for Enrichment of Evaluations (PROMETHEE), ELimination Et Choix Traduisant la Realité (ELECTRE III), Technique for Order Preferences by Similarity to Ideal Solution (TOPSIS) and Weighted Sum Algorithm (WSA) methods.

The study could reduce social conflicts among stakeholders and improve the current tools to a more sustainable implementation of future floating energy projects. The results illustrate the potential locations for deploying floating wind farms in the Canary Islands, especially in the marine areas of Gran Canaria, Fuerteventura, and Lanzarote.

The paper is composed of six sections. Section 2 presents an overview of the use of GIS and MCDM in the floating wind. Section 3 summarizes the methodology developed, data acquisition, the spatial restrictions, the evaluation criteria and the MCDM, whose implementation obtains the suitable areas. Section 4 analysis the results of the case study providing new indicators and concepts. Sections 5 and 6 discuss and conclude, respectively. 


\section{GIS and MCDM Use in Offshore Wind Planning Studies}

The planning for floating offshore wind development is often cited as a priority [8]. However, the identification of suitable locations is a complex geospatial problem. To solve the problem requires a vast knowledge of the ocean conditions and an understanding of several technical and social aspects [9]. Wrong-site selection could result in low energy extraction, displeased neighbours, low economic revenue, negative influence on other marine activities and a social discrepancy [10]. The use of a GIS-based model to the site selection is an efficient tool. This tool includes several protocols for spatial data analysis and project management [11].

An important starting point for the site selection is the knowledge of the existing energetic resource. This is normally achieved using local area atmospheric models that allow fine grid studies to be made and detailed information of the wind resource to be made available [12-19]. The wave conditions at the location are also necessary as they will govern the floating wind platforms' dynamics. Detailed information about wave conditions variability can be obtained with regional wave models, which are also used to determine wave energy availability [20-23].

Since the last years, there has been an increased use of GIS in offshore wind projects suitability studies over a huge variety of regions. Nonetheless, specific tools and methodologies for achieving the goals are still under development.

Gavériaux et al. [24] introduced a methodological framework based on the combined use of multi-criteria decision analysis (MCDA) and geographical information systems (GIS) for identifying the maritime areas the most appropriate to implement an offshore wind turbine farm in the Hong Kong bay.

Chaouachi et al. [25] proposed a multi-criteria selection approach for offshore wind sites assessment. The framework is implemented as an interactive case study for three the Baltic States.

Vagiona and Karanikolas [26] created a methodology to investigate the most efficient offshore wind farms' siting in Greece. The method integrates the AHP technique and geographic information systems tools.

Vasileiou et al. [27] presented a methodological framework for identifying the most appropriate marine areas in Greece towards the deployment of wind/waves combined systems is developed and presented. The framework combines the use of multi-criteria decision-making methods and geographical information systems.

Mekonnen and Gorsevski [28] presented a web-based participatory geographic information system (PGIS) framework intended for offshore wind suitability analysis in Lake Erie, Ohio. The model integrates GIS and decision-making tools that involve different stakeholders and the public to solve complex planning problems and build consensus.

The decision-making process starts with recognising and defining the issue, e.g., identifying suitable areas for offshore wind energy production or wave conditions. Once defined, the multicriteria decision methods focus on identifying and aggregating comprehensive sets of criteria that reflect relevance to the decision problem [29]. Evaluation criteria can contribute as added value parameters (an aspect which enhances or detracts suitability) or limitation (parameters that restrict the use and space of locations).

Recently, the use of MCDM as a tool to site and equipment selection on the offshore wind industry has endured a significant increase. These mathematical methods are consolidating itself as a tool capable of solving the problems associated with complex decision making.

Ziemba et al. [30] proposed a new multi-criteria method for sustainability assessment, PROSA. PROSA is characterized by a low degree of criteria compensation and high degree to strong sustainability.

Vagiona and Kamilakis [31] present a research study that develops and implements an integrated methodology for evaluating and prioritising appropriate sites for sustainable offshore wind farm development. The methodological framework includes the analytical hierarchy process technique for order preference by similarity to ideal solution (TOPSIS). 
Wu et al. [32] built a framework for offshore wind farm site selection decision utilizing ELECTRE-III in the intuitionistic fuzzy environment. The decision tool was applied to the coastal areas of China.

Fetanat and Khorasaninejad [33] showed a novel hybrid MCDM approach based on the fuzzy analytic network process (ANP), fuzzy decision-making trial and evaluation laboratory (DEMATEL) and fuzzy elimination and choice expressing the reality (ELECTRE) methodologies. The method is applied to assist in selecting offshore wind farm on the Persian Gulf in the southwest of Iran.

Complications arise as part of the huge number of scales and units on which the criteria are measured. The MCDM requires the homogenization of criteria under the same units. Some data are uniformly converted into standardised units (values between 1 and 5) related to the raw data density index. The criteria are combined using either multiplicative or additive models, with or without individual weightings.

The results reliability depends on the source data accuracy. The data verification in origin is essential for the general applicability on the model. Rarely, the data sources are verified by at least double-check during the data collection stage. Nonetheless, this was a requirement in the construction of the proposed model.

\section{Methodology}

The process of identifying suitable areas for floating offshore wind farms in a geographical region demands the analysis of several criteria in a long evaluation process. The process aims to identify the best sites, avoiding environmental and social obstacles to offshore wind development $[33,34]$. The GIS collects and analyses the spatial data. The criteria were extracted from literature, private entities, and national directives [11]. The data are analysed by double-checking from at least two different sources. Moreover, some data are adjusted according to the government entities/authorities [35,36]. The method combines spatial data to generate a multi-layer map.

The proposed methodology (Figure 2) is distributed into three main parts. The first phase is the data collection. This phase entails developing a GIS database (python language) followed by the standardisation and depiction of information in thematic layers. Moreover, this part involves the exclusion stage. The incompatible areas are excluded according to specific aspects previously defined.

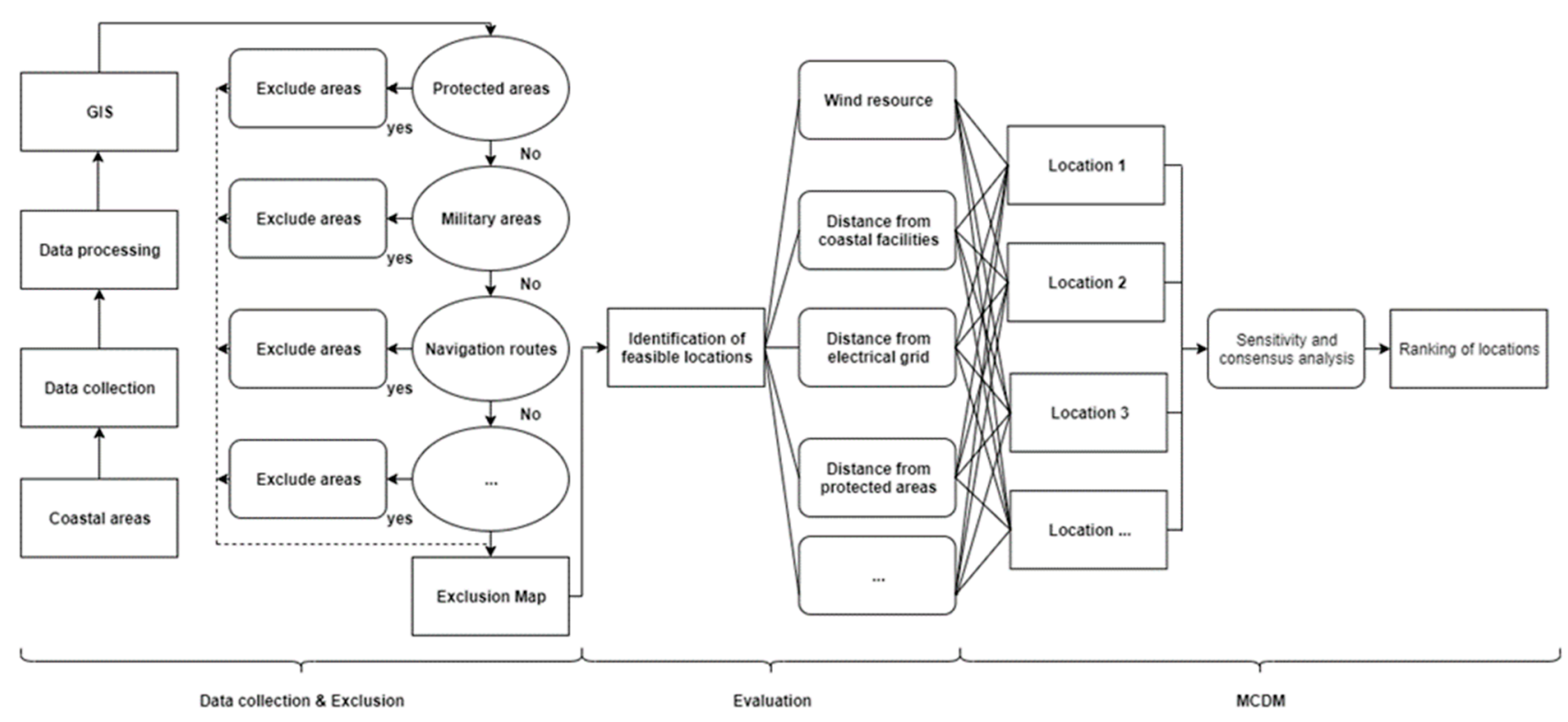

Figure 2. Flowchart of the methodological framework used in this paper.

Then, the location deemed suitable in the previous step is evaluated according to a set of criteria. In this step, some of the exclusion criteria are also used as evaluation criteria. 
Finally, the evaluation criteria are ranked based on the pairwise comparison. These comparisons are obtained from the stakeholder's perspectives. It is essential to underline that the proposed framework aims to rank the potential floating wind locations against a defined list of criteria.

\subsection{Data Collection and Exclusion Criteria}

During this first step, the data acquisition and standardisation of then was one of the main works. The data were at least double-checked from various sources. Moreover, based on the previous data were to identify those criteria that can describe multiple constraints related to floating offshore wind farm development. The constraints were also represented as individual layers in the map.

As the data were introduced in python with high fidelity (there was not a grid cells approximation), the layers correspond in a 99\% (1\% error is associated to the data sources) with the real space available for a floating farm. Several map sources were used, including wind resource, bathymetry, study area boundaries, Natura 2000, other activities, etc.

The database was organised into several layers, and the superposition of maps was used to define the suitable locations. The exclusion criteria are expressed on a Boolean model (yes/no), removing those areas where the constraints appeared [37].

This classification allows for identifying the excluded locations and good locations for floating wind farms development. Considering the levels used in other recent applications $[30,31,33,34,38]$ plus the objectives of this research, twelve main constraints criteria were used to identify the floating wind farms areas (Table 1 ).

Table 1. Main exclusion criteria.

\begin{tabular}{cc}
\hline Exclusion Criteria & Unsuitable Areas \\
\hline Military areas & All \\
Hydrocarbons and minerals & All \\
Sand and Gravel & All \\
Aquaculture and fishing & All \\
Marine renewable energies pilot zones & All \\
Environmental protected areas & All \\
Underwater lines and pipelines & $<500 \mathrm{~m}$ \\
Maritime traffic & $<500 \mathrm{~m}$ \\
Heritage areas & All \\
Wind Velocity & $<4 \mathrm{~m} / \mathrm{s}$ \\
Water Depth & $<50 \mathrm{~m} \mathrm{and}>1000 \mathrm{~m}$ \\
Distance from Shore & $<4.3 \mathrm{~nm}>200 \mathrm{~nm}$ \\
\hline
\end{tabular}

- To preserve the environment, the wind turbines should not be installed on protected landscapes.

- To preserve cultural heritage areas, an offshore wind farm installation is not contemplated.

- To reduce the impacts on other activities, wind farms should be located out of them.

- The areas with a high wind resource are highly valuable. The wind resource is a critical factor related to the economic viability of a project. In this context was used as low limit an average wind velocity of $4 \mathrm{~m} / \mathrm{s}$.

- The offshore turbines must be installed out of specific areas (anchoring, military, etc.) and respect a buffer area of $1 \mathrm{~km}$.

The criteria were represented as layers in the map produced with the Python software toolbox [39]. Figure 3 shows this step's outcome, showing the exclusion areas and the suitable locations for floating wind farms installation. 

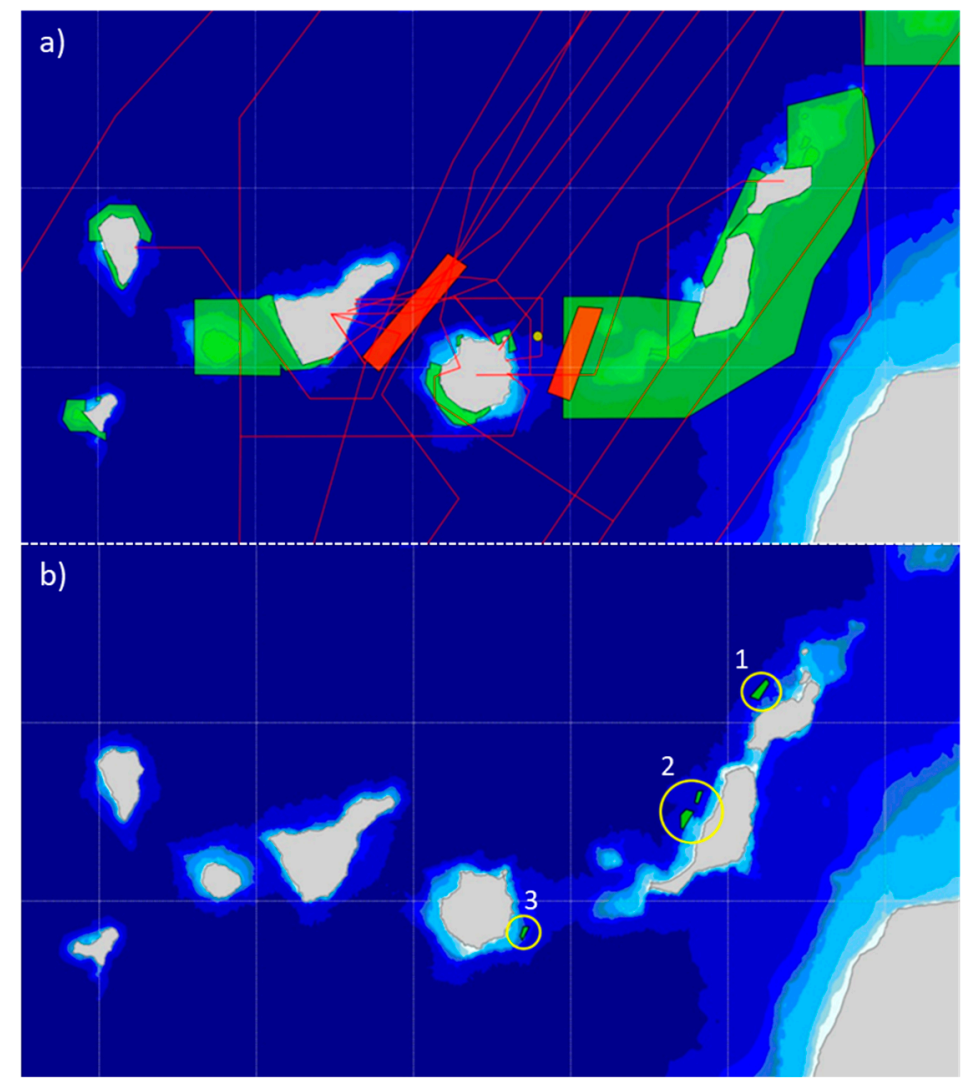

Figure 3. Some exclusion layers and the potential sites in the Canary Archipelago (latitude, longitude: 28.291565, -16.629129). (a) Protected areas (green), maritime route (orange), pilot zone (yellow) and underwater lines (red). (b) Proposed locations of Lanzarote (1), Fuerteventura 1\&2 (2) and Gran Canaria (3).

\subsection{Evaluation Criteria}

In this step of the analysis, the remaining locations are being characterised respect to specific criteria. Opposite to the exclusion criteria, which follow a Boolean form, the evaluation criteria are usually measured on a standardised unit. These criteria help to enhance with more precision the suitability of a specific location.

Two categories of criteria were used: (a) Benefit criteria: These criteria have a positive contribution, and (b) Cost criteria: Criteria that add negative aspects to the site selection (lower values are preferable than higher ones).

Six criteria comprise the selection aspects. These criteria contain certain aspects of the decision-making process associated with floating wind technology. The factors are listed in Table 2, indicating their relevance (metocean, viability, logistics, facilities, marine environment or techno-economic) and their objective associated (maximize or minimize). The evaluation criteria are not necessarily different from the exclusion, ones. Nevertheless, the decision maker's characteristics should be evaluated using a continuous function (i.e., higher preference for higher wind speed values). All the choices are evaluated by the decision-makers involved in the Arcwind project [40]. This allows specifying a compensatory decision tool. Following this compensatory process, poor performance in one criterion can be counterbalanced by an excellent performance of another criterion (see Section 4.2). 
Table 2. Evaluation criteria classification.

\begin{tabular}{cccc}
\hline Type-Criteria & & Criteria & Objective \\
\hline \multirow{5}{*}{ Metocean } & C1 & Wind velocity & Maximize \\
& C2 & Wind potential & Maximize \\
& C3 & Water depth & Minimize \\
& C4 & Wave conditions & Minimize \\
& C5 & Marine currents & Minimize \\
& C6 & Temperature & Minimize \\
\hline \multirow{2}{*}{ Viability } & C7 & Technical feasibility & Maximize \\
& C8 & Sufficient study times & Maximize \\
\hline \multirow{2}{*}{ Logistics } & C9 & Distance to local electrical grid & Minimize \\
& C10 & Distance from coastal facilities & Minimize \\
\hline \multirow{5}{*}{ Facilities } & C11 & Distance from shore & Minimize \\
& C12 & Distance from residential areas & Maximize \\
& C13 & Distance from the maritime routes & Maximize \\
& C14 & Distance from underwater lines & Maximize \\
& C15 & Distance to marine recreational activities & Maximize \\
& C16 & Distance from airport & Maximize \\
\hline \multirow{3}{*}{ Marine environment } & C17 & Distance from protected areas & Maximize \\
& C18 & Proximity to migratory birds' paths & Minimize \\
& C19 & Proximity to migratory marine life paths & Minimize \\
\hline & C20 & Area of the territory & Maximize \\
& C21 & Proximity to the area of electric demand & Maximize \\
& C22 & Population served & Maximize \\
& C23 & Multiple resources & Minimize \\
\hline
\end{tabular}

It is noteworthy that all criteria are entirely measurable easily, thus avoiding associated errors and adjusting the data.

\subsection{Pairwise Comparison and Weight Determination}

The importance of each criterion and their dominance concerning the other is to assess each criterion in term of significance from a single stakeholder perspective and with respect to other stakeholders involved in the process. In a MCDM, the discrepancies among criteria are commonly present. These scenarios show rank reversal when adding or removing specific options.

The pairwise comparison allows calculating the relative importance of each criterion. The experts involved define a one-to-one mapping between all the identified sub-criteria by a discrete set of numbers reflecting their importance.

Several experts have been involved in the AHP pairwise comparison process. The experts can be grouped as floating wind technology developers interested in securing revenues through higher production yields and minimum investments cost. But also, the group aiming to efficient energy and compliance with the existing regulatory aspects.

The weight and consensus determination are interdependent on the decision-makers and the pairwise comparison process.

Table 3 shows the scale to determine the pairwise comparisons in the AHP. A set of discrete values composes the table.

Each participant in the decision process should submit their pairwise comparisons as a final consolidated and single comparison matrix and the weighted geometric mean of all the decision matrices elements. Then, a consensus analysis provides a particular idea of consensus level reached. The AHP consensus indicator is determined through Shannon entropy [41]. 
Table 3. The Fundamental Scale for Pairwise Comparisons.

\begin{tabular}{|c|c|c|}
\hline Importance & Definition & Explanation \\
\hline 1 & Equal importance & Element $\boldsymbol{a}$ and $\boldsymbol{b}$ contribute equally to the objective \\
\hline 3 & $\begin{array}{c}\text { Moderate/weak importance of one over } \\
\text { another }\end{array}$ & Experience and judgment slightly favor element $\boldsymbol{a}$ over $\boldsymbol{b}$ \\
\hline 5 & Essential or strong importance & Experience and judgment strongly favor element $\boldsymbol{a}$ over $\boldsymbol{b}$ \\
\hline 7 & Demonstrated importance & $\begin{array}{c}\text { Element } \boldsymbol{a} \text { is favored very strongly over } \boldsymbol{b} \text {; its dominance } \\
\text { is demonstrated in practice }\end{array}$ \\
\hline 9 & Absolute importance & $\begin{array}{l}\text { The evidence favoring element over } \boldsymbol{a} \text { over } \boldsymbol{b} \text { is of the } \\
\text { highest possible order of affirmation }\end{array}$ \\
\hline $2,4,6,8$ & $\begin{array}{l}\text { Intermediate values between the two } \\
\text { adjacent judgments }\end{array}$ & $\begin{array}{l}\text { When compromise is needed. For example, } 4 \text { can be used } \\
\text { for the intermediate value between } 3 \text { and } 5\end{array}$ \\
\hline $\begin{array}{l}\text { Reciprocals of above } \\
\text { nonzero }\end{array}$ & \multicolumn{2}{|c|}{$\begin{array}{l}\text { If } a \text { has one of the above numbers assigned to it when compared with } \boldsymbol{b} \text {. Then } \boldsymbol{b} \text { has the reciprocal value } \\
\text { when compared with } \boldsymbol{a} \text {. }\end{array}$} \\
\hline Rationals & Ratios arising from the scale & $\begin{array}{c}\text { If consistency were to be forced by obtain in n numerical } \\
\text { values to span the matrix. }\end{array}$ \\
\hline$a, b$ & \multicolumn{2}{|c|}{ Each of the items that are evaluated through a pairwise comparison matrix. } \\
\hline
\end{tabular}

After the comparison matrix is consolidated, the application of Eigenvalue method determines a priority vector. This vector represents the criteria ranking by importance.

Then, the consistency ratio (CR) allows to validate or reject the comparison matrix. Consensus must be strictly distinguished from consistency. The consensus is derived from the resulting priorities and has nothing to do with the consistency ratio.

At last, sensitivity analysis helps eliminate alternatives, enhance the decision process, or provide information as to the robustness of the decision.

\subsection{Multi-Criteria Decision Making}

The multiple criteria decision rules define a relationship between the feasible locations and the final priority map. Comparing the available areas allows achieving the best location from an economic, technical, and social perspective.

In this context, all the individual evaluation criteria are compared and ranked as weight function based on the expert's considerations. In the same way, the method is also applied to analyse the locations in each single criteria function.

The AHP is a pairwise comparison method, developed by T. Saaty [42]. Each element is scored against the rest, to evaluate its relative importance. This method divides a complex problem into parts, as a hierarchy. The objective is the top of the hierarchy. The rest of the criteria are on the other levels of the base [43].

This hierarchical process through pairwise comparison uses values from Saaty's fundamental scale 1 to 9 in importance order (see Table 3).

Thereby, a matrix with a number of columns and rows proportional to criteria number is created. Then a series of successive steps are followed:

(i) The matrix is completed based on the pairwise comparisons.

(ii) The sum of elements in each column is determined.

(iii) Each matrix component is divided by the sum of its column.

(iv) Each row's mean value is calculated and noted in a new column. This column collects the priority vector of the criteria.

Moreover, the methodology AHP provides mathematical tools to measure the consistency of the comparison. This allows checking the objectivity of the process-The consistency index calculation following the next steps:

- The sum of the matrix elements is multiplied by the relative weight of the respective criterion.

- The products for all columns are added and defining the result as $\lambda_{\max }$. Then, the consistency index (CI) is defined through Equation (1) given by [44]: 


$$
C I=\frac{\lambda_{\max }-n}{n-1}
$$

where $n$ is the number of criteria.

The comparison matrix inputs are randomly selected. The results are obtained through a simulation with Equation (1). Complementary, the results level of consistency is obtained from the consistency ratio $(C R)$ (see Equation (2)). The $C R$ should have a value inferior to $0.1[44]$ :

$$
C R=\frac{C I}{R I}
$$

The random index $(R I)$ is correlated with the number of matrix elements. The $R I$ used was proposed by [45].

The priority vector of each criterion is used in the other MCDM's: PROMETHEE, ELECTRE III, TOPSIS and WSA (Weighted Sum Algorithm). These methods are applied to assess the global hierarchical ranking of the proposed floating wind farms locations.

\subsubsection{PROMETHEE}

PROMETHEE is a multi-criteria decision-making method developed by Brans et al. [46]. An outranking methodology is used to order the alternatives combined in a non-complex form. The method is useful, where a finite number of alternatives are to be ranked considering several criteria.

The PROMETHEE method follows five steps. In the first step, a preference function showing the preference of the decision-maker for action a regarding another action $b$, will be defined separately:

$$
p[f(a), f(b)]=p[f(a)-f(b)]
$$

The second step compares the suggested alternatives in pairs to the preference function. As a third step, the results of these comparisons are presented in an evaluation matrix as the estimated values of every criterion for every alternative. The fourth step includes the PROMETHEE I method application for partial ranking, and afterwards, the fifth step includes the PROMETHEE II method for the complete ranking of the alternatives.

\subsubsection{ELECTRE III}

This technique, developed by Roy [47], uses pairwise comparison through concordance and discordance indexes. The concordance index shows that alternative a is better than alternative $b$ in terms of weights sum. The discordance index represents the absolute difference of the alternative pair divided by the maximum difference over all pairs. The global concordance index $C_{i k}$ shows that the value supporting the concordance among all criteria under the hypothesis that $A_{i}$ outranks $A_{k}$, can be defined as follows:

$$
C_{i k}=\sum_{j=1}^{m} W_{j} c_{j}\left(A_{i} A_{k}\right) / \sum_{j=1}^{m} W_{j}
$$

where $W_{j}$ is the weight for the $j$ th criterion. To determine the relation among alternatives outranking respect to a threshold value for the indexes can be performed.

\subsubsection{TOPSIS}

TOPSIS method was developed by Hwang and Yoon [48]. This method uses the concept of distance maximization from the negative-ideal solution and minimization of the distance from the positive-ideal solution. The alternative must be as close as possible to the positive-ideal solution and as far as possible from the negative-ideal solution. The positive-ideal solution contents the maximal benefit solution. The negative-ideal solution represents a minimal benefit solution. Proximity of alternatives to the ideal solution $S_{i}^{*}$ and 
the negative-ideal solutions $S_{i}^{-}$can be obtained using the square root of squared distances in the imaginary attribute space given in Equations (5) and (6):

$$
S_{i}^{*}=\sqrt{\sum_{j=1}^{n}\left(v_{i j}-v_{j}^{*}\right)^{2}}
$$

Similarly, the separation from the negative-ideal solution A - is given in Equation (6):

$$
S_{i}^{-}=\sqrt{\sum_{j=1}^{n}\left(v_{i j}-v_{j}^{-}\right)^{2}}
$$

where $v_{i j}$ represents the value of the $i$ th alternative corresponding to the $j$ th criterion. $v_{j}^{*}$ and $v_{j}^{-}$are the positive-ideal and negative-ideal values of the $j$ th criterion, respectively.

\subsubsection{WSA}

WSA was proposed by MacCrimon in 1968. WSA is known as the weighted linear combination, weighted sums, or scoring method [49]. WSA employs the principle of weighted average. This simple method is based on a scaled value is given for each alternative by an attribute. Scaled values are then multiplied by their respective weight assigned by the decision maker, as shown in Equation (7):

$$
A_{j}=\operatorname{Max} \sum_{i=1}^{j} a_{i j} w_{j}
$$

where $A_{j}$ is the alternative score, $a_{i j}$ is the actual value of the $i$ th alternative concerning the $j$ th criterion, and $w_{j}$ is the weight of the $j$ th criterion. The result sums up the total obtained values and the criterion weight. The highest score is considered the best alternative.

The algorithm proposed by each method corresponds to the operating concept proposed. AHP divides the problem into several hierarchy levels before justifying the best solution. PROMETHEE focuses on the differences between criteria. ELECTREE attempts to explain the preference on the basis of concordance and discordance indexes. TOPSIS presents an idea of distance-based decision-making. Lastly, WSA uses the weighted average principle. Despite the differences between methods, these techniques have contributed significantly to the effectiveness of decision making from the site selection perspective.

The MCDM has been applied to developing a proper software interface for supporting the implementation of the AHP and the secondary MCDM plus the expert's evaluations. This tool can help the decision making due to improved analyses based on inconsistency, consensus, and sensitivity analyses.

\section{Application of the Selection Framework in the Canary Islands}

In the developed framework, with the implementation of 23 evaluation criteria, including wind velocity, temperature, distance from shore, water depth, distance to maritime routes, the distance to the airport, multiple resource use, distance from the protected areas, etc. was possible to identify the locations priority order. After using the geographical information system (GIS) method to determine the suitable regions for installing the floating wind turbines, the MCDM applied with the evaluation criteria results in a final ranking of locations. This ranking permit to classify the sites in order of suitability for a future offshore wind installation.

\subsection{Suitable Areas}

Four floating offshore wind farm sites have been identified as technically feasible after analysis and evaluation of the Canary Islands EEZ. Moreover, several factors that characterise the suitability of maritime space to offshore wind installation were identified. Consequently, when applying the proposed model for floating wind farm site selection, some aspects should be amended according to the new scenario's features (e.g., national and local regulations). 
The resultant zones cover $144 \mathrm{~km}^{2}$ of the total area studied. The entire space could host the installation of 60 floating wind turbines. Due to their dimensions for potential siting of a wind farm, the locations obtained would cause minor effects in the maritime space's operation. Table 4 shows the suitable areas for the installation of the floating wind farms in the Canary Islands.

Table 4. Geographic coordinates (WGS84) for all the corners of the four proposed locations.

\begin{tabular}{ccc}
\hline Location & Latitude & Longitude \\
\hline \multirow{3}{*}{ Lanzarote } & 29.15 & -13.86 \\
& 29.25 & -13.76 \\
& 29.22 & -13.74 \\
Fuerteventura(1) & 29.13 & -13.80 \\
\hline \multirow{3}{*}{ Fuerteventura(2) } & 28.62 & -14.19 \\
& 28.62 & -14.16 \\
& 28.55 & -14.19 \\
& 28.55 & -14.21 \\
\hline & 28.48 & -14.30 \\
Gran Canaria & 28.52 & -14.27 \\
& 28.50 & -14.22 \\
& 28.40 & -14.29 \\
& 28.41 & -14.30 \\
\hline & 27.86 & -15.30 \\
& 27.86 & -15.26 \\
\hline
\end{tabular}

The Canary Islands sites are located mainly in the archipelago's east area, at an average distance from shore of $8 \mathrm{~km}$. The wind velocity is relatively high, reaches an average of $8.6 \mathrm{~m} / \mathrm{s}$ in all locations. Moreover, the average wind potential is $4826 \mathrm{~h} / \mathrm{yr}$. These four locations are also affected by the lowest significant wave height average of the six regions studied, $1.7 \mathrm{~m}$. However, the average water depth is concentrated between the $400 \mathrm{~m}$ of Gran Canaria and $800 \mathrm{~m}$ of Fuerteventura and Lanzarote locations (Table 5).

\subsection{AHP and Other Methods}

The reason for weighting the relevant criteria and sub-criteria via a panel of 5 experts wherein the average comments of individuals was the basis of priority criteria. According to the results, it was observed that the most useful criterion in the wind farms site selection is metocean data (Table 6). Besides, the two factors wind velocity and wind potential were the most critical effective sub-criteria in the floating wind farm site selection. The weights obtained from the paired comparison in the AHP method is in accordance with Table 6, depicting options of each sub-criterion. The consistency ratio value is 0.01 below the limit of 0.1 .

It is visible that the leading interest for this wind farms is situated in the Gran Canaria location, followed by Lanzarote site. Table 7 shows the ranking positions of the four offshore wind sites obtained with the AHP method compared to the ranking of the other four methods. As it can be seen, the AHP rank is equal with the ELECTRE III, PROMETHEE, TOPSIS and WSA methods. 
Table 5. Evaluation parameters for the Canary Islands locations.

\begin{tabular}{|c|c|c|c|c|c|}
\hline \multirow[t]{2}{*}{ Criteria } & \multirow[t]{2}{*}{ Units } & \multicolumn{4}{|c|}{ Locations } \\
\hline & & Lanzarote & Fuerteventura (1) & Fuerteventura (2) & Gran Canaria \\
\hline Wind velocity & $\mathrm{m} / \mathrm{s}$ & 8.65 & 8.62 & 8.62 & 8.63 \\
\hline Wind potential & $\mathrm{h} / \mathrm{yr}$ & 4998 & 4718 & 4703 & 4885 \\
\hline Water depth & $\mathrm{m}$ & 800 & 800 & 500 & 400 \\
\hline Wave conditions & $\mathrm{m}$ & 1.850 & 1.722 & 1.708 & 1.602 \\
\hline Marine currents & $\mathrm{m} / \mathrm{s}$ & 0.4 & 0.3 & 0.3 & 0.4 \\
\hline Temperature & ${ }^{\circ} \mathrm{C}$ & 23.4 & 23.6 & 23.6 & 23.8 \\
\hline Technical feasibility & density & 3 & 3 & 3 & 5 \\
\hline Sufficient study times & density & 3 & 3 & 3 & 3 \\
\hline Distance to local electrical grid & $\mathrm{km}$ & 23 & 30.7 & 36.4 & 13.1 \\
\hline Distance from coastal facilities & $\mathrm{km}$ & 76 & 73.2 & 87 & 9.7 \\
\hline Distance from shore & $\mathrm{km}$ & 9.6 & 12.8 & 13.6 & 8.2 \\
\hline Distance from residential areas & $\mathrm{km}$ & 9.7 & 13.2 & 14.4 & 8.4 \\
\hline Distance from maritime routes & $\mathrm{km}$ & 12.9 & 15.5 & 14.8 & 1.5 \\
\hline Distance from underwater lines & $\mathrm{km}$ & 7.6 & 9.4 & 4.6 & 1.6 \\
\hline Distance to marine recreational activities & $\mathrm{km}$ & 1.7 & 5.2 & 6.4 & 0.4 \\
\hline Distance from airport & $\mathrm{km}$ & 27.2 & 31.5 & 35.8 & 11.2 \\
\hline Distance from protected areas & $\mathrm{km}$ & 2.4 & 1.5 & 1.5 & 5.7 \\
\hline Proximity to migratory birds' paths & density & 1 & 1 & 1 & 1 \\
\hline Proximity to migratory marine life paths & density & 1 & 1 & 1 & 1 \\
\hline Area of the territory & $\mathrm{km}^{2}$ & 50.3 & 24.5 & 42.3 & 26.4 \\
\hline Proximity to the area of electricity demand & $\mathrm{km}$ & 27.5 & 30.9 & 36.6 & 32.6 \\
\hline Population served & number & 145,084 & 107,521 & 107,521 & 845,195 \\
\hline Multiple resources & density & 1 & 1 & 1 & 1 \\
\hline
\end{tabular}

Table 6. The effective weight of criteria and sub-criteria.

\begin{tabular}{|c|c|c|c|}
\hline Criteria & Weight & Sub-Criteria & Weight \\
\hline \multirow{6}{*}{ Metocean } & \multirow{6}{*}{0.295} & Wind velocity & 0.073 \\
\hline & & Wind potential & 0.094 \\
\hline & & Water depth & 0.038 \\
\hline & & Wave conditions & 0.051 \\
\hline & & Marine currents & 0.028 \\
\hline & & Temperature & 0.010 \\
\hline \multirow{2}{*}{ Viability } & \multirow{2}{*}{0.104} & Technical feasibility & 0.066 \\
\hline & & Sufficient study times & 0.038 \\
\hline \multirow{2}{*}{ Logistics } & \multirow{2}{*}{0.102} & Distance to local electrical grid & 0.053 \\
\hline & & Distance from coastal facilities & 0.048 \\
\hline \multirow{6}{*}{ Facilities } & \multirow{6}{*}{0.237} & Distance from shore & 0.033 \\
\hline & & Distance from residential areas & 0.032 \\
\hline & & Distance from the maritime routes & 0.030 \\
\hline & & Distance from underwater lines & 0.042 \\
\hline & & Distance to marine recreational activities & 0.035 \\
\hline & & Distance from airport & 0.065 \\
\hline \multirow{3}{*}{ Marine environment } & \multirow{3}{*}{0.148} & Distance from protected areas & 0.064 \\
\hline & & Proximity to migratory birds' paths & 0.043 \\
\hline & & Proximity to migratory marine life paths & 0.041 \\
\hline \multirow{4}{*}{ Techno-economic } & \multirow{4}{*}{0.114} & Area of the territory & 0.035 \\
\hline & & Proximity to the area of electric demand & 0.031 \\
\hline & & Population served & 0.017 \\
\hline & & Multiple resources & 0.031 \\
\hline
\end{tabular}


Table 7. Ranking of locations with the different multicriteria decision methods.

\begin{tabular}{|c|c|c|c|c|c|c|}
\hline \multirow{2}{*}{ Ranking } & \multirow{2}{*}{ Locations } & AHP & ELECTRE III & PROMETHEE & TOPSIS & WSA \\
\hline & & Score & Rank & Score & Score & Score \\
\hline 1 & Gran Canaria & 0.297216 & 1 & 0.51534 & 0.64327 & 0.47398 \\
\hline 2 & Lanzarote & 0.257344 & 2 & 0.42241 & 0.39724 & 0.40300 \\
\hline 3 & Fuerteventura (2) & 0.224692 & 3 & 0.30248 & 0.3956 & 0.32306 \\
\hline 4 & Fuerteventura (1) & 0.220748 & 4 & 0.30212 & 0.36432 & 0.28216 \\
\hline
\end{tabular}

Figure 4 displays the preference ranking according to the AHP method for the floating wind farms in the Canary Islands. In general, it can be said that the results are similar. Generally, in the literature, there are some discordances with the results of the AHP and other MCDM. In this case, the accordance between results can be seen as a consistency of the methodology and criteria selected.

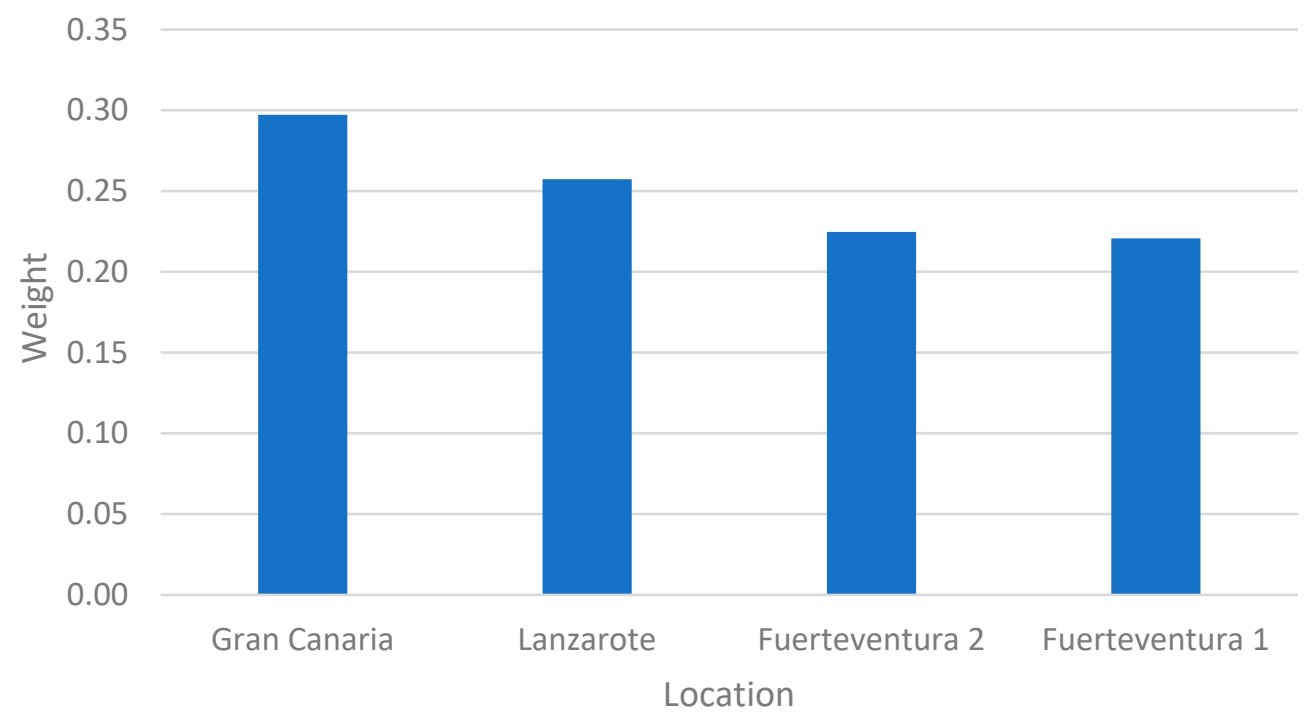

Figure 4. Locations weight using the analytic hierarchy process (AHP). The locations are weightranked in the following order, Gran Canaria (0.297), Lanzarote (0.257), Fuerteventura 2 (0.224) and Fuerteventura 1 (0.220).

\subsection{Consensus Analysis}

The group decision making is a process dominated by the interaction between selection and consensus. The consensus analysis in AHP-MCDM is a separate process. The row geometric mean method using Shannon entropy allows for consensus control. The Shannon entropy as a diversity index for the distribution of priorities among criteria permits obtains an index for relative homogeneity as a consensus indicator. Using this indicator, we can evaluate decision-makers' group and gain a deeper about the judgment and decision process.

The decision-makers opinions can be evaluated towards reaching valuable insights into their behaviour. This allows quickly modifying their weights accordingly, to balance the perceived bias. At this stage, a decision-maker analysis is carried out based on their inputs related to criteria and locations evaluation (see Figure 5).

The consensus related to the criteria importance is $44 \%$ between the experts. This value is meagre but is coherent with each stakeholder's different background and the different point of view related to site selection priorities. Nevertheless, on evaluating locations based on each criterion, the percentage of consensus between the various stakeholders reaches a value of up to $96 \%$. 


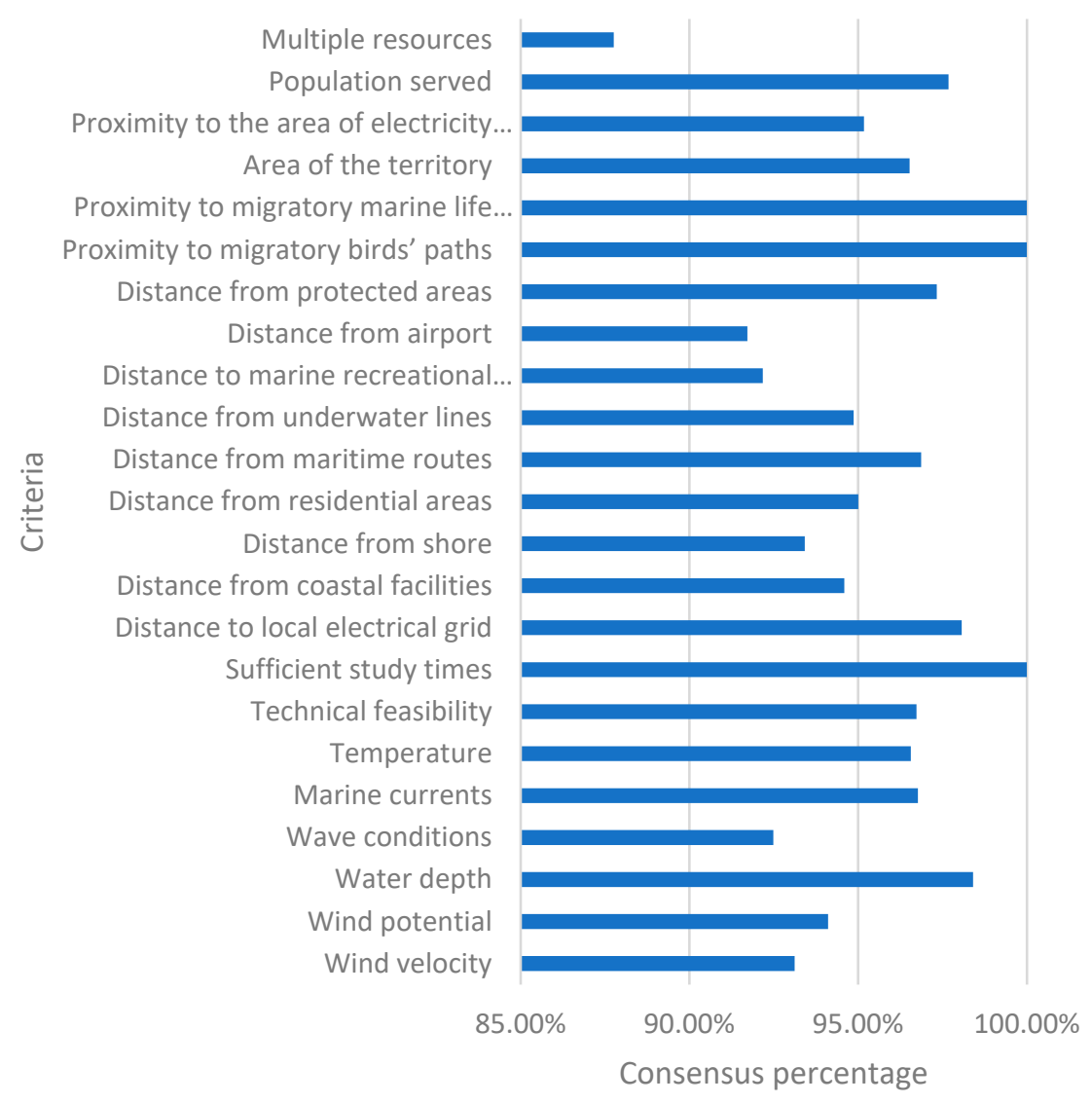

Figure 5. Consensus percentage related to analytic hierarchy process evaluation of locations.

\subsection{Sensitivity Analysis}

Several scenarios were used for the sensitivity analysis implementation. These scenarios implement different criterion weight. Apart from an equal-weighted scenario, simple variation and Ensslin formulation [50] apply to a pair of upper and lower criteria were engaged. This scenario remains identical to the original AHP ranking. Table 8 shows the relative importance of the criteria using different weight scenarios.

Table 8. Criteria relative importance in the different sensitivity analysis scenarios.

\begin{tabular}{|c|c|c|c|c|c|c|c|}
\hline \multirow{2}{*}{\multicolumn{2}{|c|}{ Criteria }} & \multicolumn{2}{|c|}{ Simple Variation } & \multicolumn{2}{|c|}{ Ensslin Formulation } & \multirow{2}{*}{\multicolumn{2}{|c|}{ Ranking }} \\
\hline & & $10 \%$ & $20 \%$ & $10 \%$ & $20 \%$ & & \\
\hline \multirow{2}{*}{ High weight } & $\mathrm{C} 1$ & unchanged & unchanged & unchanged & unchanged & 1 & Gran Canaria \\
\hline & $\mathrm{C} 2$ & unchanged & unchanged & unchanged & unchanged & 2 & Lanzarote \\
\hline \multirow{2}{*}{ Low weight } & $\mathrm{C} 22$ & unchanged & unchanged & unchanged & unchanged & 3 & Fuerteventura(2) \\
\hline & $\mathrm{C} 23$ & unchanged & unchanged & unchanged & unchanged & 4 & Fuerteventura(1) \\
\hline
\end{tabular}

Even though the weighting of the C1, C2, C22 and C23 was varied from $10 \%$ to $20 \%$, the global results did not suffer variations. The results demonstrate the model robustness. The fluctuations of criteria weight result in not changes in the ranking of locations.

\section{Discussion}

Floating wind farm site selection requires the consideration of numerous, seemingly incompatible data sets. Using GIS technologies and MCDM techniques to integrate data sets and assess evaluation criteria can generate useful databases and outputs for energy developers and maritime planners. 
In general, the Canary Islands region offers relatively suitable conditions for floating wind development. However, consistent with other regions worldwide [20,23,24], existing users and uses of the marine environment severely restrict potential sites where development can occur with minimal mediation between conflicting user groups.

The $143.5 \mathrm{~km}^{2}(0.03 \%$ of area considered) evaluated to be of good suitability for floating wind provide coastal managers with enough scope to be somewhat flexible within an integrated maritime spatial planning strategy. The analysis integrated traditional data sets (e.g., constraint layers, wind speed, water depth) and introduced novel data sets to offshore wind planning. The identification of suitable marine regions using GIS principles, though relatively common, has not previously been applied to floating wind farms site selection (to the authors' knowledge). Additionally, the application of layers representing project viability, marine environment and techno-economic aspects are a new concept with minimise negative impacts and maximise the floating wind farms installations. Despite the extent, the GIS-based model does not imply value estimations within the region but identifies locations where beneficial criteria may be maximised while maintaining sustainability. This tool's use allows introducing specific conditions of each region [11] while guarantees the overall model stability.

In terms of the accuracy of the outcomes, this investigation uses data from different sources with different accuracy levels. The errors from anyone map layer will have propagated through the analysis and, combined with other layers error, may cause inaccuracies in the output map. Nevertheless, to avoid these problems, all data were at least compared in two different data sources. In other words, the errors in the offshore wind farm site map are minimum.

In this paper, the evaluation of floating wind farms locations is considered a multicriteria decision-making problem that involves multiple and conflicting attributes. The multi-criteria decision-making methods were designed to help them make more informed choices in a step-by-step manner. The multi-criteria decision-making methods have been proposed for energy resources allocation, evaluation, and selection locations; however, no studies have been done in the field of floating wind farms.

The decision matrices typically consist of vagueness and uncertainty. Thus, the results obtained by the AHP are compared with PROMETHEE, ELECTRE III, TOPSIS and WSA methods. Several analyses have been performed to contrast the results with the different MCDM methods. The results of the MCDM methods are subjected to a study of consensus and sensitivity. It can be noticed that for the consensus analysis, the correlation of the results is above $87 \%$. This percentage represents a quasi-total agreement between decisionmakers. While in the case of the sensitivity analysis, the model guarantees robustness with variations in results of up to $20 \%$.

Besides this, with AHP, PROMETHEE, ELECTRE III, TOPSIS and WSA methods, the results' correlation is maintained at $100 \%$. These results indicate that the five MCDM present similar outcomes for the best places to install a floating wind farm.

It is not straightforward for floating wind experts to make consistent decisions when faced with unfamiliar problems involving trade-offs between the advantages and disadvantages. Discussion of the results with the expert participants confirmed that they consider these factors in the following order: first met the ocean, followed by facilities, marine environment viability and logistics.

The study contributes to the newly added credibility of expert validation of the existing literature about GIS-based renewable energy suitability studies. This is the first research to evaluate the most suitable floating wind farms using GIS-MCDM, specifically. The results support Spain's government's future decision-making when building more renewable energy infrastructures based on offshore wind power plants concerning the traditional energy model. 


\section{Conclusions}

The paper presents a methodological framework for floating wind farms site selection based on the combined use of GIS and MCDM. As a result, the most appropriate marine areas in the Canary Islands towards offshore wind turbines have been obtained. The main conclusions of this study are as follows:

- Four areas for the installation of floating wind farms in the Canary Islands have been identified. All areas located in the regions in the East part of the archipelago.

- The areas identification was considerably limited by huge marine protected areas and water depths up of $1000 \mathrm{~m}$. Marine regions with a vast wind resource were excluded due to the limitations of the areas.

- The offshore area, located South of Gran Canaria, presents the best space for the siting of floating wind farm. This is due to the high values of this area respect to the evaluation criteria study.

- The offshore sites located in the East of Lanzarote and Fuerteventura islands also present a high potential for the installation of floating turbines. The main reason is the significant wind resource existent. At the same time, other criteria are also adequately satisfied.

- Implementing AHP in terms of weights' determination helped by a GIS database can significantly reduce the subjectivity in judgments during the pairwise comparisons. The subjectivity is also reduced due to the quantitative character of the evaluation criteria.

- The application of other MCDM obtaining the same results confirms the model robustness. Nevertheless, these results are related to the characteristics of the proposed area. In other regions with different areas characteristics, the results could suffer variations.

- A sensitivity analysis was performed on criteria, to gauge if the solution is implementable and robust. Sensitivity analysis is a critical step, whose purpose is to assess the stability under changes in the parameters.

The paper illustrates the potential of deploying floating wind turbines in the Canary Islands. However, the installation of a floating project in Spain requires at a governmental level the existence of a legal framework that includes the spatial planning of marine energy projects and a simple process for energy projects licensing.

This paper proves multi-criteria analysis strength to serve energy planners, national authorities, and scholars a precise tool for decision making. The expert's involvement facilitates marine areas selection by considering the social, technical, economic, and environmental aspects. Considering the subjectivity and the complexity that characterize the social factors, public surveys could be included in future steps.

Moreover, the methodology presented can be easily applied to other regions, only introducing simple variations.

Author Contributions: Conceptualisation of the problem was developed by H.D. and C.G.S. The MCDM analysis was performed by H.D. The writing of the original draft manuscript was done by H.D. and C.G.S. All authors have read and agreed to the published version of the manuscript.

Funding: This work was conducted within the ARCWIND project-Adaptation and implementation of floating wind energy conversion technology for the Atlantic region (EAPA 344/2016), which is co-financed by the European Regional Development Fund through the Interreg Atlantic Area Programme. This work contributes to the Strategic Research Plan of the Centre for Marine Technology and Ocean Engineering (CENTEC), which is financed by the Portuguese Foundation for Science and Technology (Fundação para a Ciência e Tecnologia-FCT) under contract UIDB/UIDP/00134/2020.

Institutional Review Board Statement: Not applicable.

Informed Consent Statement: Not applicable.

Data Availability Statement: Not applicable.

Conflicts of Interest: The authors declare no conflict of interest. 


\section{References}

1. Montelongo, G.; Romero, C.; Tena, R. The Canary Islands. In Seas at the Millennium: An Environmental Evaluation: 1. Regional chapters: Europe, The Americas and West Africa; Sheppard, C., Ed.; Elsevier: Oxford, UK, 2000; pp. 185-199.

2. United Nations Framework Convention on Climate Change Paris Agreement; United Nations: Paris, France, 2016.

3. Gobierno de Canarias Anuario Energético de Canarias 2017; Gobierno de Canarias: Lanzarote, Spain, 2017.

4. Gobierno de Canarias Estrategia Energetica de Canarias 2015-2025; Gobierno de Canarias: Lanzarote, Spain, 2017.

5. Schallenberg-Rodríguez, J.; Notario-del Pino, J. Evaluation of on-shore wind techno-economical potential in regions and islands. Appl. Energy 2014, 124, 117-129. [CrossRef]

6. Bagbanci, H.; Karmakar, D.; Guedes Soares, C. Review of offshore floating wind turbines concepts. In Maritime Engineering and Technology; Guedes Soares, C., Ed.; Taylor \& Francis Group: London, UK, 2012; pp. 553-562, ISBN 9780415621465.

7. Uzunoglu, E.; Karmakar, D.; Guedes Soares, C. Floating Offshore Wind Platforms. In Floating Offshore Wind Farms; Castro-Santos, L., Díaz-Casas, V., Eds.; Springer International Publishing: Cham, Switzerland, 2016; pp. 53-76.

8. European Commission SET-Plan Offshore Wind Implementation Plan; European Commission: Brussels, Belgium, 2018.

9. Díaz, H.; Fonseca, R.B.; Guedes Soares, C. Site selection process for floating offshore wind farms in Madeira Islands. In Advances in Renewable Energies Offshore, Proceedings of the 3rd International Conference on Renewable Energies Offshore(RENEW 2018), Lisbon, Portugal, 8-10 October 2018; Guedes Soares, C., Ed.; Taylor \& Francis Group: London, UK, 2019; pp. $729-737$.

10. Ten Brink, T.S.; Dalton, T. Perceptions of commercial and recreational fishers on the potential ecological impacts of the Block Island Wind Farm (US). Front. Mar. Sci. 2018, 5, 439. [CrossRef]

11. Díaz, H.; Guedes Soares, C. An integrated GIS approach for site selection of floating offshore wind farms in the Atlantic continental European coastline. Renew. Sustain. Energy Rev. 2020, 134, 110328. [CrossRef]

12. Salvação, N.; Bernardino, M.; Guedes Soares, C. Validation of a regional atmospheric model for assessing the offshore wind resources along the Portuguese coast. In International Conference on Offshore Mechanics and Arctic Engineering; ASME Paper OMAE 2013-11631; ASME: Nantes, France, 2013; pp. 1-11.

13. Salvação, N.; Bernardino, M.; Guedes Soares, C. Assessing mesoscale wind simulations in different environments. Comput. Geosci. 2014, 71, 28-36. [CrossRef]

14. Salvação, N.; Bernardino, M.; Guedes Soares, C. Assessing the offshore wind energy potential along the coasts of Portugal and Galicia. In Developments in Maritime Transportation and Exploitation of Sea Resources; Guedes Soares, C., Pena, F.L., Eds.; Taylor \& Francis Group: London, UK, 2014; pp. 995-1002. [CrossRef]

15. Salvação, N.; Guedes Soares, C. Wind resource assessment offshore the Atlantic Iberian coast with the WRF model. Energy 2018, 145, 276-287. [CrossRef]

16. Martín Mederos, A.C.; Medina Padrón, J.F.; Feijóo Lorenzo, A.E. An offshore wind atlas for the Canary Islands. Renew. Sustain. Energy Rev. 2011, 15, 612-620. [CrossRef]

17. Onea, F.; Ciortan, S.; Rusu, E. Assessment of the potential for developing combined wind-wave projects in the European nearshore. Energy Environ. 2017, 28, 580-597. [CrossRef]

18. Veigas, M.; Iglesias, G. Wave and offshore wind potential for the island of Tenerife. Energy Convers. Manag. 2013, 76, 738-745. [CrossRef]

19. Campos, R.M.; Guedes Soares, C. Assessment of three wind reanalyses in the North Atlantic Ocean. J. Oper. Oceanogr. 2017, 10, 30-44. [CrossRef]

20. Guedes Soares, C.; Bento, A.R.; Gonçalves, M.; Silva, D.; Martinho, P. Numerical evaluation of the wave energy resource along the Atlantic European coast. Comput. Geosci. 2014, 71, 37-49. [CrossRef]

21. Gonçalves, M.; Martinho, P.; Guedes Soares, C. Assessment of wave energy in the Canary Islands. Renew. Energy 2014, 68, 774-784. [CrossRef]

22. Gonçalves, M.; Martinho, P.; Guedes Soares, C. Wave energy assessment based on a 33-year hindcast for the Canary Islands. Renew. Energy 2020, 152, 259-269. [CrossRef]

23. Rodriguez, G.; Clarindo, G.; Guedes Soares, C. Wave energy potential assessment along the west coast of Fuerteventura. In Progress in Renewable Energies Offshore; Guedes Soares, C., Ed.; Taylor \& Francis Group: London, UK, 2016; pp. 37-44. [CrossRef]

24. Gavériaux, L.; Laverrière, G.; Wang, T.; Maslov, N.; Claramunt, C. GIS-based multi-criteria analysis for offshore wind turbine deployment in Hong Kong. Ann. GIS 2019, 25, 207-218. [CrossRef]

25. Chaouachi, A.; Covrig, C.F.; Ardelean, M. Multi-criteria selection of offshore wind farms: Case study for the Baltic States. Energy Policy 2017, 103, 179-192. [CrossRef]

26. Vagiona, D.G.; Karanikolas, N.M. A multicriteria approach to evaluate offshore wind farms siting in Greece. Glob. Nest J. 2012, 14, 235-243.

27. Vasileiou, M.; Loukogeorgaki, E.; Vagiona, D.G. GIS-based multi-criteria decision analysis for site selection of hybrid offshore wind and wave energy systems in Greece. Renew. Sustain. Energy Rev. 2017, 73, 745-757. [CrossRef]

28. Mekonnen, A.D.; Gorsevski, P.V. A web-based participatory GIS (PGIS) for offshore wind farm suitability within Lake Erie, Ohio. Renew. Sustain. Energy Rev. 2015, 41, 162-177. [CrossRef]

29. San Cristóbal Mateo, J.R. Multi-Criteria Analisys in the Renewable Energy Industry; Springer: London, UK, 2012; ISBN 978-1-4471-2345-3.

30. Ziemba, P.; Wątróbski, J.; Zioło, M.; Karczmarczyk, A. Using the PROSA method in offshore wind farm location problems. Energies 2017, 10, 1755. [CrossRef] 
31. Vagiona, D.G.; Kamilakis, M. Sustainable site selection for offshore wind farms in the South Aegean-Greece. Sustainability 2018, 10, 749. [CrossRef]

32. Wu, Y.; Zhang, J.; Yuan, J.; Geng, S.; Zhang, H. Study of decision framework of offshore wind power station site selection based on ELECTRE-III under intuitionistic fuzzy environment: A case of China. Energy Convers. Manag. 2016, 113, 66-81. [CrossRef]

33. Fetanat, A.; Khorasaninejad, E. A novel hybrid MCDM approach for offshore wind farm site selection: A case study of Iran. Ocean Coast. Manag. 2015, 109, 17-28. [CrossRef]

34. Tsoutsos, T.; Tsitoura, I.; Kokologos, D.; Kalaitzakis, K. Sustainable siting process in large wind farms case study in Crete. Renew. Energy 2015, 75, 474-480. [CrossRef]

35. Soro Mateo, B. La autorización de parques eólicos marinos en España. Rev. Catalana Dret Ambient. 2011, 2, 1-43.

36. The Ministry of Infrastructure and the Environment; White Paper on Offshore Wind Energy: Hague, The Netherlands, 2014.

37. Baban, S.M.J.; Parry, T. Developing and applying a GIS-assisted approach to locating wind farms in the UK. Renew. Energy 2001, 24, 59-71. [CrossRef]

38. Mahdy, M.; Bahaj, A.B.S. Multi criteria decision analysis for offshore wind energy potential in Egypt. Renew. Energy 2018, 118, 278-289. [CrossRef]

39. Python Software Foundation Python Software. Available online: https:/ / www.python.org/ (accessed on 31 July 2018).

40. ARCWIND Project ARCWIND Project. Available online: http://www.arcwind.eu/ (accessed on 31 July 2018).

41. Shannon, C.E. A Mathematical Theory of Communication. Bell Syst. Tech. J. 1948, 27, 379-424. [CrossRef]

42. Saaty, T.L. Decision making with the Analytic Hierarchy Process. Int. J. Serv. Sci. 2008, 1, 83-98. [CrossRef]

43. Saaty, R.W. The analytic hierarchy process-what it is and how it is used. Math. Model. 1987, 9, 161-176. [CrossRef]

44. Setiawan, A.; Sediyono, E.; Moekoe, D.A. Application of AHP Method in Determining Priorities of Conversion of Unusedland to Food Land in Minahasa Tenggara. Int. J. Comput. Appl. 2014, 89, 37-44. [CrossRef]

45. Alonso, J.A.; Lamata, M.T. Consistency in the analytic hierarchy process: A new approach. Int. J. Uncertain. Fuzziness Knowl.Based Syst. 2006, 14, 445-459. [CrossRef]

46. Brans, J.P.; Vincke, P.; Mareschal, B. How to select and how to rank projects: The PROMETHEE method. Eur. J. Oper. Res. 1986, 24, 228-238. [CrossRef]

47. Roy, B. Classement et choix en présence de points de vue multiples. Rev. Française D'informatique Rech. Opérationnelle 1968, 2 , 57-75. [CrossRef]

48. Hwang, C.L.; Masud, A.S.M. Multiple Objective Decision Making-Methods and Applications; Springer: Berlin, Germany, 1979; Volume 1, ISBN 9783540091110.

49. MacCrimmon, K.R. Decision Making among Multiple-Attribute Alternatives: A Survey and Consolidates Approach; Corporation, T.R., Ed.; The Rand Corporation: Santa Monica, CA, USA, 1968.

50. Ensslin, L.; Montibeller Neto, G.; Noronha, S.M. Decision Support: Methodology for Structuring Problems and Multicriteria Evaluation of Alternatives; Florianópolis Insular, Ed.; Insular: Mullingar, Brazil, 2001. (In Portuguese) 